\title{
Chrétien de Troyes - Godefroy de Leigni, Il Cavaliere della carretta (Lancillotto)
}

\section{Maria Colombo Timelli}

\section{(2) OpenEdition}

1 Journals

\section{Édition électronique}

URL : http://journals.openedition.org/studifrancesi/32778

DOI : 10.4000/studifrancesi.32778

ISSN : 2427-5856

Éditeur

Rosenberg \& Sellier

\section{Édition imprimée}

Date de publication : 1 décembre 2005

Pagination : 611-612

ISSN : 0039-2944

\section{Référence électronique}

Maria Colombo Timelli, «Chrétien de Troyes - Godefroy de Leigni, I/ Cavaliere della carretta

(Lancillotto) », Studi Francesi [En ligne], 147 (XLX | III) | 2005, mis en ligne le 30 novembre 2015, consulté le 20 avril 2021. URL : http://journals.openedition.org/studifrancesi/32778 ; DOI : https:// doi.org/10.4000/studifrancesi.32778

Ce document a été généré automatiquement le 20 avril 2021.

\section{(c)}

Studi Francesi è distribuita con Licenza Creative Commons Attribuzione - Non commerciale - Non opere derivate 4.0 Internazionale. 


\title{
Chrétien de Troyes - Godefroy de Leigni, Il Cavaliere della carretta (Lancillotto)
}

\author{
Maria Colombo Timelli
}

\section{RÉFÉRENCE}

CHRÉTIEN DE TROYES - GODEFROY DE LEIGNI, Il Cavaliere della carretta (Lancillotto), a cura di G. PIETRo BeLtRAMI, Alessandria, Edizioni dell'Orso («Gli Orsatti - Testi dell’Altro

Medioevo», 23), 2004, pp. 427

1 Après un travail de réflexion duré 25 ans, P. Beltrami nous livre son édition-traduction du Chevalier de la Charrette. Basée sur l'édition Poirion (Pléiade 1994), elle est précédée de deux chapitres introductifs. Dans le premier, consacré aux questions littéraires, Beltrami maintient un heureux équilibre entre esprit de divulgation et sérieux scientifique. Il donne une analyse détaillée du roman, mais ne renonce pas à souligner la complexité de certains aspects - entre autres, la combinaison des deux éléments, anthropologique et courtois - et n'hésite pas à renvoyer à la riche réflexion critique dont la Charrette a fait l'objet (cf. la Bibliographie réunie aux pp. 419-26); de même, il prend des positions qui révèlent la profonde connaissance du texte de la part d'un critique raffiné. Sur le plan stylistique, Beltrami souligne surtout l'extrême recherche rhétorique du texte de Chrétien, qui constitue, on le croit sans peine, un véritable défi pour le traducteur. La deuxième partie de l'introduction concerne les aspects plus strictement philologiques: tradition textuelle, choix de l'édition de base, discussion détaillée des leçons adoptées par Poirion et amendées par Beltrami.

2 La traduction en italien, publiée en regard sur la page de droite, est rimée, en vers de neuf syllabes, 'novenari' à accent libre et à rime plate: on y retrouve la facilité apparente de Chrétien, ainsi que son style 'moyen', sa langue coulante qui file sans accroc. 
3 Le texte est accompagné de nombreuses notes en bas de page, où l'on trouvera: la discussion de certaines traductions ou interprétations douteuses, des commentaires lexicologiques, ainsi que des informations manifestement adressées à des non spécialistes de la langue ou de la littérature françaises médiévales, d'une utilité certaine dans cette collection.

4 La réussite de la traduction est telle que le texte italien en arrive à rivaliser avec l'original de Chrétien. 